\title{
Sustainable space system planning on urban disaster prevention and hazard assessment: a case study of Tainan metropolis, Taiwan
}

\author{
T.-Y. Chen ${ }^{1,2}$, Y.-K. Chen ${ }^{2}$, P.-K. Tseng ${ }^{3,4}$, C.-H. Tu ${ }^{5}$ \\ \& F.-Y. Shyr ${ }^{5}$ \\ ${ }^{1}$ Tainan City Government, Taiwan \\ ${ }^{2}$ Department of Architecture, National Cheng Kung University, Taiwan \\ ${ }^{3}$ Building Management Section of Public Works Bureau, \\ Tainan City Government, Taiwan \\ ${ }^{4}$ Department of Land Management and Development, \\ Chang-Jung Christian University, Taiwan \\ ${ }^{5}$ Department of Urban Planning, National Cheng Kung University, \\ Taiwan
}

\begin{abstract}
This empirical research is based on the relevant theoretical research and previous circumstances to develop a case study to explore in space planning for disaster prevention and relief. The research aims to establish a database system of disaster prevention and rescue sites for urban disaster prevention planning in Tainan metropolis, Taiwan. Historical data of Tainan metropolis were analyzed to construct a customized disaster information system. Through constructing a disaster prevention and rescue site system, a service size of fundamental refuge rings in Tainan metropolis was calculated, and influences on hazard sites and potentials of flood hazard toward refuge sites were evaluated. Using the software of MapInfo as an external platform for the database and MapBasis as internal system content, we develop a customized model for Tainan metropolis based on its refuge shelters, hazard sites, rescue locations, route system, and resources. The system provides city government officers and rescue sectors with space information, specific site inquiry, and detailed information of a particular site. This research also proposes some strategies for space planning on disaster prevention and rescue sites.
\end{abstract}

Keywords: space planning, disaster prevention, database system, hazard assessment. 


\section{Introduction}

Natural disasters take place frequently in Taiwan. A high efficient precaution system would provide instant information and suggest urgent strategies to eliminate the damages. A fully-functional database would be beneficial to administrators. Various disaster characteristics across counties and cities and environmental differences should be incorporated into the database system. Calculating numbers of refuge sites, rescue sites and hazard building locations with techniques of Geographic Information System (GIS), we can precisely provide space information to assist municipal administrators and rescue teams for in-time strategic planning for preventing catastrophes and reducing possible damages.

\section{Literature review}

The following literature review include the discussions of definitions regarding urban disaster prevention planning, refuge shelters, refuge route planning, and an introduction to two existing database systems called Taiwan Earthquake Loss Estimation System and Vehicle through Electronic Network of Disaster Geographical Information.

\subsection{Definitions of urban disaster prevention planning}

From a narrow point of view, relevant urban space, city facilities, shared device and building should be incorporated into an urban disaster prevention planning to cope with typhoons, floods, earthquakes, fires, and hazard disasters. The works should include prevention, rescue, and post-construction after disasters. With a broad definition, the urban disaster prevention planning should include (1) city administration; (2) river and creek administration (i.e., river preparation, hillside collapse, coast prevention and reconstruction); and (3) road administration (i.e. road planning, road facilities, and preventions from disasters). Precautions discussed above should be integrated into the macro-prevention system. The urban disaster prevention planning should be consistent and comprehensive considering all levels of factors. The integrated plan should also be practical, efficient, and effective [1, 2].

\subsection{Refuge shelters}

The definition of the refuge shelters refers to facilities that provide refuge, relief, and first aids for people who are injured during disasters [3, 4].

\subsection{Refuge routes for relief}

Three types of routes including roads for disaster rescue, refuge routes, and alternative routes should be planned in advance. Refuge roads for relief should include roads providing disaster relief, take refuge in the road and substituting the road. Roads designed for providing disaster relief should enable rescue teams 
to deliver relief goods, equipments, and personnel. Those roads should also make the process of fire fighting efficient. Refuge routes should contribute to the minimum damage and safe way to reach the refuge shelters. These routes should be planned depending on conditions of road, importance ranking of the city, and population density.

\subsection{Taiwan earthquake loss estimation system (TELES)}

TELES is designed by the National Centre for Research on Earthquake Engineering (NCREE). The initial system came from the analysis structure of both HAZ-Taiwan (Hazard Taiwan) and HAZUS (Hazard United States). The assessments help to evaluate and analyze degrees of disaster losses. Techniques of Microsoft Visual C ++ and MapInfo MapBasic were employed in the design to develop a software measuring and simulating severity of earthquake losses in Taiwan. Applications provide users to evaluate early stages of a disaster, disaster scenario simulations and risk assessments [5].

Fourteen categories of information in the TELES are summarized as follows: (1) Medical Care Facilities (2) Emergency Response Facilities (3) Schools (4) Hazardous Materials Facilities (5) Potable Water Pipeline Segments (6) Potable Water Facilities (7) Waste Water Pipeline Segments (8) Waste Water Facilities (9) Crude and Refined Oil Pipe Segments (10) Crude and Refined Oil Facilities (11) Natural Gas Pipeline Segments (12) Natural Gas Facilities (13) Electric Power Facilities (14) Communication Facilities. The main purpose the TELES is to supply in-time relief through relevant information to accelerate rescue work. Potential negative consequences are minimized. In addition, the database of TELES offers resources that enable researchers to study and analyze the modules of planning basic information as follows: (1) Disasters rescue unit(s) (2) Medical unit(s) (3) Refuge shelter(s) (4) Hazard buildings (5) Usage of fire control bolt and urgent water (6) Route conditions (7) Rescue disasters resources (i.e. human resource and goods) (8) Feedback information about disaster (9) Profile(s) of rescue teams (10) Accommodation and shelter allocation.

\subsection{Vehicle through electronic network of disaster geographical information (VENTEN)}

The database of VENTEN was developed by the Asian Japan disaster reduction centre (ADRC). This information administration system consists of a network server of an internet (Web server), a geographical server of information system (GIS server), and a database server (DBS server). The system works through remote sensing, air photograph technology and in-time video monitoring. It also allows transmission through the network. VENTEN system can be operated as ideal interface, optimizing the precaution effects because of in-time information integration $[6,7]$. 


\section{Regional and disaster characteristics of Tainan metropolis, Taiwan}

Tainan metropolis lies in the centre of the largest plain in the south of Taiwan, Next to Kaohsiung, it is the second largest metropolis in the southern Taiwan. From its south to Kaohsiung is about fifty kilometres, and from its north to Chiayi is around sixty-five kilometres. It is divided into six administrative districts, including the east, the south, the north, the centre-and-western district, Annan, and Anping district with a total 17,564.56 hectares. Among these districts, Annan district is the largest one accounting for $61.03 \%$ of the Tainan metropolis. The second largest is the south district with $15.52 \%$. The centre district, the smallest one, accounts for $1.53 \%$.

In the report of the fourth main project of comprehensive review in Taiwan which was released in January of 2003, fires, soil liquefaction, tsunami, and earthquakes happened in Tainan because of its geographical location leaning to the Pacific Ocean, abundant fish pools. During typhoon seasons, floods are frequent phenomena [8].

\section{Taiwan systematic structure of database}

\subsection{Structure of the planned database system}

The steps are as follows: Historical data of Tainan metropolis were entered into the database of disaster relief. Five subsystems are introduced as follows [9].

(1) System of city refuge shelters: Shelter sites consist of parks, stadiums, schools, and parking areas.

(2) System of rescue and/or prevention sites: It provides disaster relief with hospitals/clinics, material units, telecommunication, and water-supplying units.

(3) Emergency system and non-governmental resources: Recourses include fire control department, police stations, human resource from nongovernmental organizations, and information units [10].

(4) Potential hazard spots: Patrol stations, special industrial corporations, and electric units.

(5) Refuge and alternative routes: Roads for disaster rescue, refuge routes, and alternative routes are included.

\subsection{System for administrators}

An authorized user name and passwords will be identified before an administrator is allowed to use and revise the system. Selective main functions are introduced here. In the following, tools are first summarized: [11].

(1) Basic tools: Functions include file opening, storing, and duplication.

(2) Main tools: Numeric values and figures can be depicted through choosing, enlarging, narrowing the particular data sets. 
(3) Drawing tools: Functions, such as drawing, revision, typing in, labelling of the figure and materials are commonly used.

(4) Main functions: Inquiry regarding refuge shelters, hazard sites, the inquiry of disaster relief units, road system, and table/figure configuration can be made.

(5) Main pictorial selection: Centre lines of roads, the urban plan, police stations, service stations, stadiums, schools, river systems, and the regional boundaries can be depicted.

(6) Specific inquiry:

1. The inquiry of refuge shelters: A particular park, stadium, school, or parking area can be assessed.

2. The inquiry of hazard sites: An individual station of patrol, natural gas, special industry, or electricity can be examined.

3. The inquiry of providing disaster relief units: A specific institution, police station, fire control, non-governmental organization, and military division can be inquired.

4. The inquiry of route system: Particular roads for disaster rescue, refuge routes, and alternative routes can be verified.

(7) The materials form listing:

Similar functions as what previously discussed in (6) are supplied.

\section{Disaster relief simulations from the database with data of Tainan metropolis}

The database of space for prevention is constructed based on the geographical information system (GIS). The content includes the system of urban disaster prevention planning and the network concept of disaster geographic information. Information regarding disaster-rescuing and refuge sites, emergency shelters, refuge routes, hazard sites, and reinforcement locations is provided. The simulations exhibit from Figures 1 to 2.

\subsection{Analysis of disaster relief route in Tainan metropolis}

The system of rescue routes should be designed depending on different districts. Refuge routes mainly rely on suburbs outside the city centre. Rescue routes should be based on those roads from fire control locations to proposed refuge areas. Rescue and alternative route system is drawn in Figure 3.

\subsection{Hazard assessments of buildings in Tainan: take partial neighbourhoods of the east district as an instance}

Similar to Nantou County, Tainan metropolis is located in the second seismic zone of earthquakes, and is close to the Hou-Jia and the fault of Shin-Hwan. Over the 6th scale earthquake occurred in Nantou County before. Similar earthquakes are expected in Tainan. For the risk assessment, results from our empirical study suggest precautions should be taken through classifications of 
planned risk neighbourhood areas. Figure 4 demonstrates risk neighbourhoods of Quan-Nan, Da-Miao, and Wei-Xiz, and possible damage situations of building when the 6th level magnitude of earthquake is simulated.

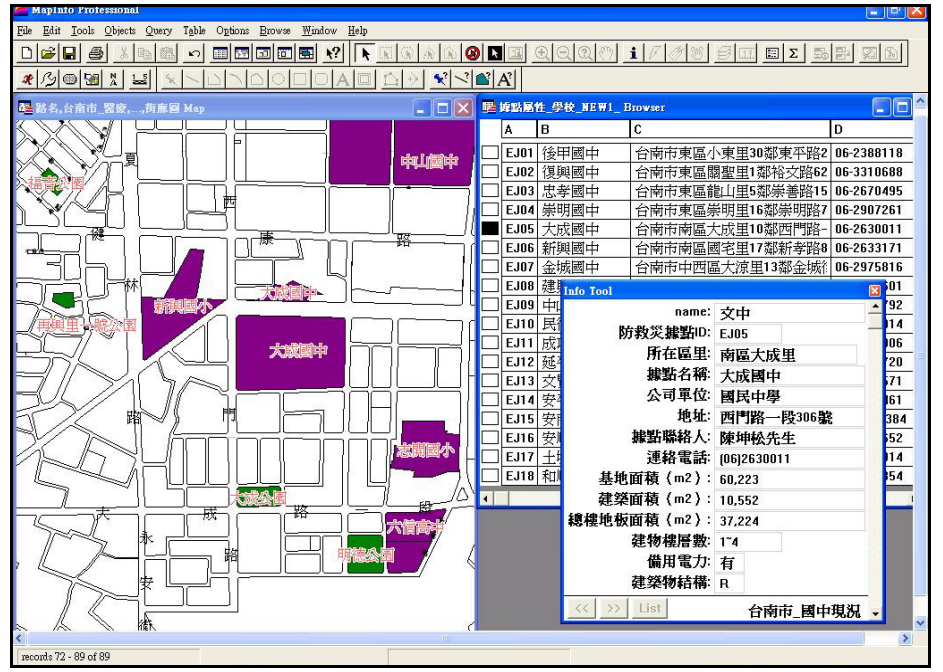

Figure 1: The inquiry of a junior high school (Take Da-Cheng junior high school as an example).

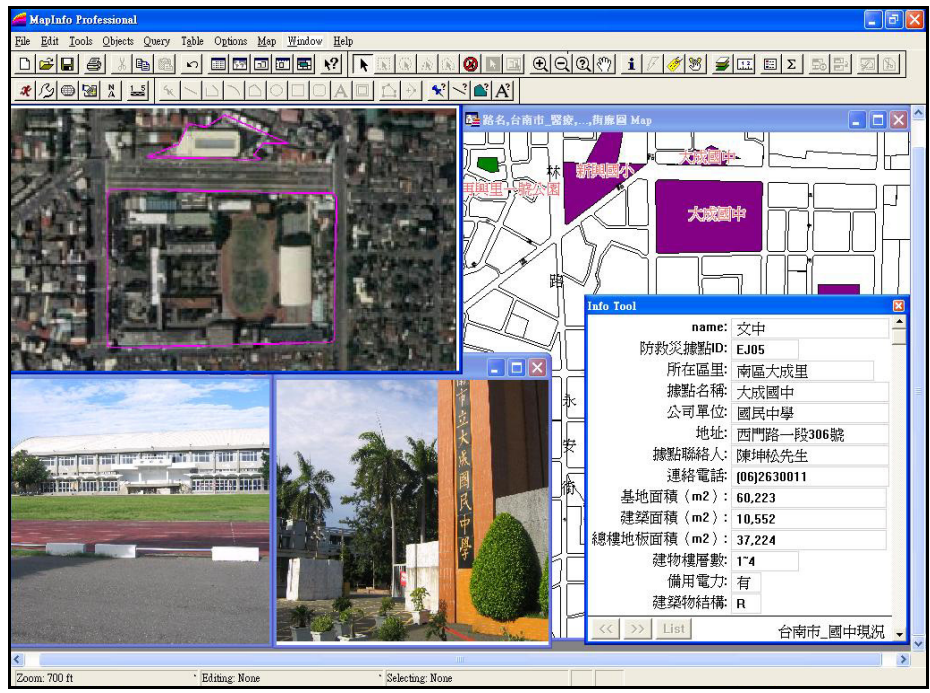

Figure 2: All base material information exhibits site information, file image. 


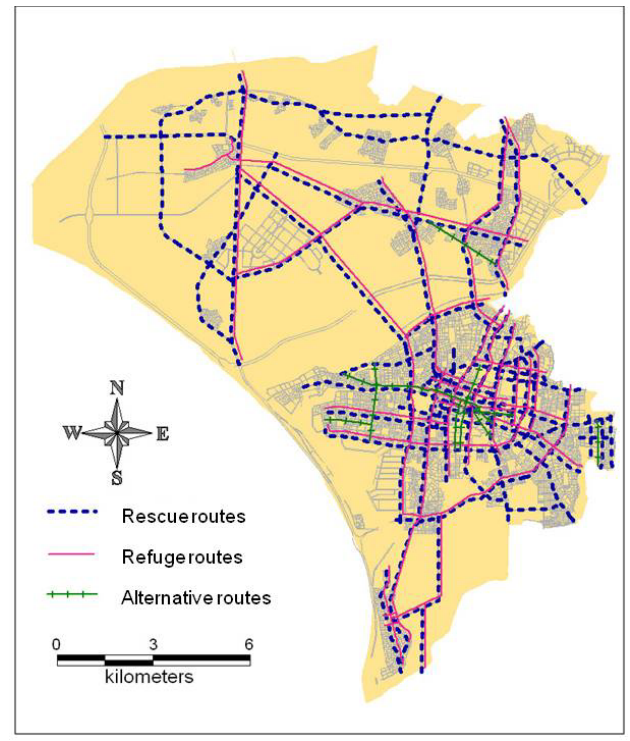

Figure 3: All base material information exhibits site information, file image.

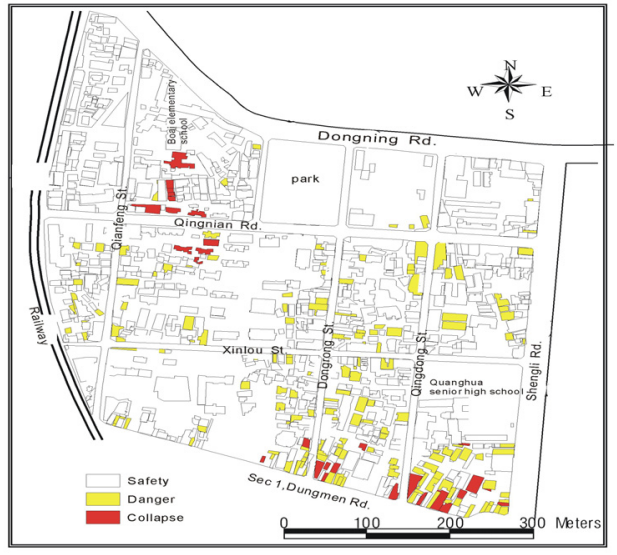

Figure 4: Distribution of the Hazard buildings in the east district, Tainan.

\subsection{Analysis of space hazard potentials}

In addition to open space, influences of hazard locations and flood hazard potentials should be incorporated into the plan on refuge shelters to eliminate human injuries and possession losses. Figures 5 to 6 show influential degrees of these two factors. 


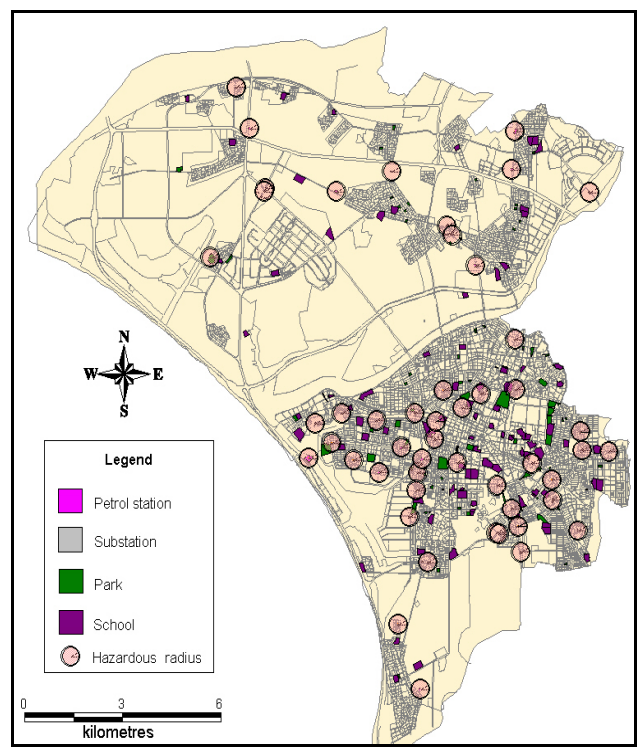

Figure 5: Distribution of the hazard buildings in the east district, Tainan.

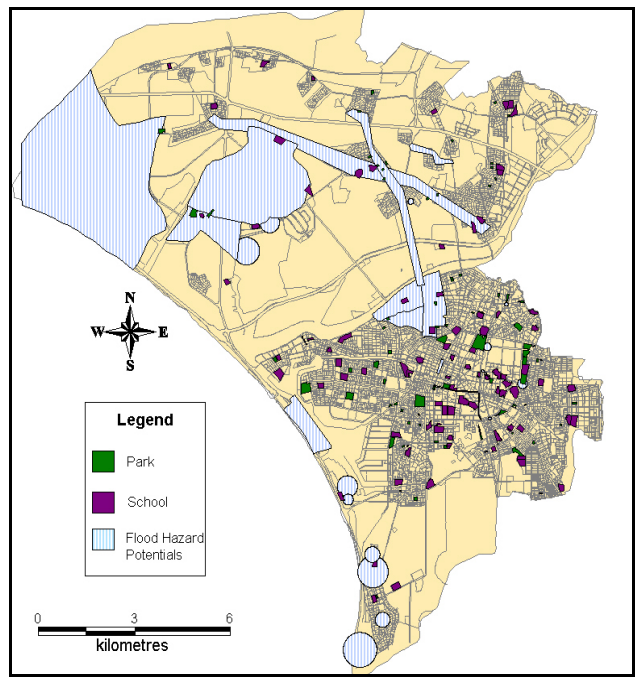

Figure 6: Risk assessment of influence from flood hazard potentials. 


\section{Conclusion and suggestion}

This empirical research is based on the relevant theoretical research and previous circumstances to develop a case study to explore in space planning for disaster prevention and relief. Historical data of Tainan city were analyzed to construct a customized disaster information system.

Using the software of Mapinfo as an external platform for the database and MapBasis as internal system content, we develop a customized model for Tainan metropolis based on its refuge shelters, hazard sites, rescue locations, route system, and resources. The system provides city government officers and rescue sectors with space information, specific site inquiry, and detailed information of a particular site. Meanwhile, information integrated from TELES is also provided by the system. Categories of attributes from TELES are considered.

This research proposed a database for administrative purpose to analyze data efficiently and effectively. A comprehensive urban disaster prevention plan will provide precise and valuable rescue strategies for emergency.

The data in the proposed database is not complete. The following directions should be considered in future research:

1. The network formats the picture shelf of number value should be set up with the instant transmission function on the internet.

2. Decision and support system need to be incorporated.

3. Space information of various types of cities could be an additional factor in the planning.

4. Instant image monitoring should be introduced into the system.

5. Renewal and maintenance of instant information.

6. Disasters simulation with detailed historical data.

7. Information regarding migration of rescue sites should be updated.

8. Neighbour cities should be incorporated into the system.

9. Regional disaster prevention database should be integrated into the decision system for public policy makers and government officers.

\section{References}

[1] Arai, K., Terayama, Y., Disaster-Related Information Clearing House, Information Technology for Disaster Management, 1:19-24, 2001.

[2] Chang, Y.-S., The research on the planning of urban disaster-prevention. Published by Architecture and Building Research Institute of Ministry of the Interior, 1998.

[3] Huang, D.-G., Ho, M.-C., A study of disaster protection of urban planning, Architecture and Building Research Institute of Ministry of the Interior, 1997.

[4] Zhang, Z.-Y., Hazard analysis and its application in earthquake. Published by Tong-Ji University, 1995. 
[5] Chen, L.-Q., Qiu, C.-P., The evaluation of urban inducing earthquake disaster, Published by the Preparatory Office of Architecture and Building Research Institute, 1994, (in Chinese).

[6] Ding, Y.-Q., The internal and foreign research of urban disaster prevention information network, Published by Architecture and Building Research Institute of Ministry of the Interior, 2000.

[7] Rudyanto, B., Suzuki H., Ogawa, Y., Takeda, A., Yoshikawa, S., Development of Disaster Information Management Systems in Asia by Using Internet GIS, Information Technology For Disaster Management, 1:1-11, 2001.

[8] Tainan City Government, the 4th main project of comprehensive review in Tainan City, 2003.

[9] Hung, H. C., Chen, L. C., The application of seismic risk-benefit analysis to land-use planning in Taipei City, Disasters, 31:256-276, 2007.

[10] Winston, S. Federal Agencies Copy FEMA's Disaster Prevention Plan, New York: The McGraw-Hill Companies, Inc, 1999.

[11] Fang Zheng Company, MapInfo Professional User's Guide of Chinese Version, New York, 1998. 